\title{
Comparative Study of Data Elements and Data Analysis Methods in Myocardial Infarction Registry in Selected Countries and Iran
}

\author{
Hamidreza Tadayon, ${ }^{1,2}$ (i) Masoumeh Sadeghi ${ }^{3}$, Sakineh Saghaeiannejad Isfahani4(i), Mahmoud Keyvanara ${ }^{*}$ (i) \\ Monireh Sadeqi Jabali1 1 (i)
}

1- PhD Student of Health Information Management, Kashan University of Medical Sciences, Kashan, Iran.

2- Instructor, Department of Health Information Technology, Neyshabur University of Medical Sciences, Neyshabur, Iran.

3- Professor, Cardiac Rehabilitation Research Center, Cardiovascular Research Institute, Isfahan University of Medical Sciences, Isfahan, Iran.

4- Assistant Professor, Health Information Technology Research Center, Isfahan University of Medical Sciences, Isfahan, Iran.

5- Associate Professor, Social Determinants of Health Research Center, Isfahan University of Medical Sciences, Isfahan, Iran.

ABSTRACT

Introduction: Cardiovascular diseases have high morbidity and mortality rate. Disease registry system is a clinical information system designed and implemented for patient information management and one of the essential steps in its implementation is the analysis of collected data. Since the basis of data collection in each data registry system is data element, this research was conducted to compare data elements and data analysis in myocardial infarction registry system in selected countries and Iran.

Material and Methods: This research was applied in a comparative way. The research community included the registry of myocardial infarction in the United States, Switzerland, Malaysia and Iran. The data collection method was to study the documentation and interview with the registry specialists and analyze the findings was done by drawing comparative tables.

Results: Of the 26 extracted data elements, there were only 16 cases in Iran's registry system. In all registry systems, data elements were defined in the data dictionary in order to unify the definitions. Data analysis was done regularly in all three countries of the United States, Switzerland and Malaysia, but in Iran, data analysis was limited to the number of patients and the distribution of age and sex of patients.

Conclusion: In this study, an overview of the data elements and the method of data analysis in the myocardial infarction registry system was presented that could be used in designing this registry system.
Article History

Received: 2018-08-15

Accepted: 2018-10-05

Published: 2018-11-04

\section{Keywords}

Myocardial Infarction

Disease registry

Data analysis

Comparative study

(i) Please cite this article as:

Tadayon HR, Sadeghi M, Saghaeiannejad Isfahani S, Keyvanara M, Sadeqi Jabali M. Comparative Study of Data Elements and Data Analysis Methods in Myocardial Infarction Registry in Selected Countries and Iran. Iran J Med Inform. 2018; 7(1): e5. DOI: 10.24200/ijmi.v7i0.151

\footnotetext{
* Corresponding Author: M Keyvanara, Associate Professor, Social Determinants of Health Research Center, Isfahan University of Medical Sciences, Isfahan, Iran. (Email: Keyvanara@mng.mui.ac.ir) 


\section{INTRODUCTION}

Cardiovascular disease, a group of cardiovascular disorders, is the leading cause of death worldwide [1]. Cardiovascular diseases account for about one third of the world's deaths and are the leading cause of death and disability in developed and developing countries [2]. Among cardiovascular diseases, acute coronary syndrome (ACS) includes myocardial infarction (MI) and unstable angina [3]. It is one of the most important causes of mortality and morbidity and has a significant economic burden due to the costs of hospitalization, unemployment, and the follow-up of disability and long-term treatment [4]. According to the American College of Cardiology, myocardial infarction includes part of the heart muscle necrosis due to ischemia (inadequate blood circulation). The disease can be detected by clinical findings and clinical manifestations, including electrocardiogram findings, elevated levels of biochemical markers of heart muscle necrosis or medical imaging [1] .

In Iran, about 3.6 million people are admitted annually in hospitals affiliated with the Ministry of Health, many of whom are cardiovascular patients, and especially those with acute coronary syndrome [ $\underline{5}$ ]. In a study in Iran, the incidence of cardiovascular disease was reported to be 1,436 and 1,168 people per 100,000 men and women [6]. According to the Ministry of Health, nearly $40 \%$ of deaths in Iran are due to CVDs, which is the leading cause of death in the country, which means that one in three deaths is due to CVDs [7].

Given the global epidemiological data, rapid prevention of CVDs seems evident []. In this regard, systems with the longitudinal and systematic record of data can provide a true view of clinical care, the outcomes of illness and effectiveness of the treatment over time [9]. The system of registry in the field of public health and medicine is organized and defined as a system for the collection, storage, retrieval, analysis and distribution of individual information of patients with a specific disease or exposure to a specific situation that causes health-related events [9]. The disease registry system is a powerful tool for observing disease trends; understanding changes in treatment and its outcomes; examining factors affecting prognosis and quality of life; describing care patterns such as appropriate care, access to treatment, and differences in care provision; evaluation effectiveness; monitoring of safety and behavior through data feedback [10].

By designing and implementing a system for recording myocardial infarction, it is possible to determine the number and timing of the disease in the country and to identify the most atrisk populations [11].

Since many data are produced in medicine, there is always a significant gap between data collection and interpretation until it is understood. As a result, one of the main steps in designing a registry system is to determine the minimum data sets [12], which provides a standard method for collecting key data elements, making it easy to understand and compare data [1]ㅡ. On the other hand, the design and implementation of a national registry system should not be limited to the collection of disease data, but should include data analysis and information distribution [14]. Analysis of data collected in the registry system is one of the main stages in the implementation of the registry system, which can lead to improved data management related to the process or the occurrence of disease [15]. Due to the lack of myocardial infarction registry in Iran and considering the essential steps in designing and implementing any disease registry system, determining the minimum data set and how to analyze the data collected in the registry system, this study aims to study and comparing the data elements and the method of analyzing collected data in registry systems in selected countries with the current situation in Iran.

\section{MATERIAL AND METHODS}

The present study was applied and performed in a comparative way and was conducted by studying and comparing the national registry system in selected countries. In order to investigate the present status of data elements and how to analyze the myocardial infarction data in Iran due to the absence of a national registry system for myocardial infarction (according to the Oral Inquiry from the Ministry), the disease registry system in Isfahan as the first registry system of myocardial infarction in the country was studied by referring to the Cardiovascular Research Center of Isfahan.

Subsequently, MI patients were studied in Malaysia, Switzerland and the United States (a country from the Asian continent, a country from the continent of Europe and a country from the Americas). The reason for choosing these countries was their pioneering and advanced healthcare careers in their continent and better researcher access to information about their registry system.

Data collection in selected countries was through the study of articles, journals, websites and other printed and electronic documents, and in some cases corresponded to the data centers in these countries, in addition to data collection in Iran through a semi-structured interview with a researcher-designed openended questionnaire, the registrant of myocardial infarction was registered at the registry center. In addition to the interview, one of the researchers paid attention to the ways in which data were recorded, information items, the existence of a data dictionary, how to analyze data and how to produce and distribute reports. In order to analyze the findings, comparative tables were used and the ways of and differentiating them were used. To confirm the validity and reliability of the study, we tried to use authoritative sources such as websites and reliable vocabularies. All of the legal and ethical standards found in the sources of the countries studied were considered in this research.

\section{RESULTS}

The results showed that in all studied countries, a single format for data elements is collected and reported across the coverage centers. In order to uniform the data definitions, all the data elements are defined in the data dictionary of the registry system. Table 1 shows the comparison of data elements in the myocardial infarction registry system in the studied countries.

In the Swiss registry system, only the date of the first echocardiography is recorded in the data element of the date and time of the action.

The results of the study showed that in the system of registry of myocardial infarction in Malaysia, the data element of the complications in the hospital, only internal bleeding, the data element of the therapeutic and diagnostic procedures, only the invasive therapy and electrocardiography and the data element, date and time of the actions, only the date and the bypass and the date and time of coronary intervention through the skin are included in the emergency situation.

In the investigated registry system in Iran, data element of advices given to the patient during discharge is just including the cardiac rehab and data element of diagnostic and procedure codes also is just including diagnose codes. 
According to the results, registration of the data element of the date and time of starting the drugs in the Malaysian and Iranian registry system and the data element of the date and time of the actions in Iran are carried out roughly.

Also, the study of myocardial infarction record in the United States suggests that the data element of the diagnosis and action code is optional.

Table 1: Comparison of data elements of myocardial infarction registry system in selected countries.

\begin{tabular}{|c|c|c|c|c|c|}
\hline º & Data Elements & $\stackrel{5}{\infty}$ & 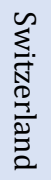 & 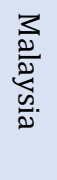 & 气ี \\
\hline 1 & Demographic data & $\checkmark$ & $\checkmark$ & $\checkmark$ & $\checkmark$ \\
\hline 2 & $\begin{array}{l}\text { Data on patient status during } \\
\text { admission }\end{array}$ & $\checkmark$ & $\checkmark$ & $\checkmark$ & $\checkmark$ \\
\hline 3 & $\begin{array}{l}\text { Date and time of onset of } \\
\text { symptoms in the patient }\end{array}$ & $\checkmark$ & $\checkmark$ & $\checkmark$ & $\checkmark$ \\
\hline 4 & $\begin{array}{l}\text { Date and time of patient } \\
\text { admission }\end{array}$ & $\checkmark$ & $\checkmark$ & $\checkmark$ & $\checkmark$ \\
\hline 5 & $\begin{array}{ll}\text { Initial diagnosis during } \\
\text { admission }\end{array}$ & - & $\checkmark$ & $\checkmark$ & - \\
\hline 6 & Data on the patient's condition & $\checkmark$ & $\checkmark$ & - & $\checkmark$ \\
\hline 7 & $\begin{array}{llll}\text { Patient History and Risk } \\
\text { Factors }\end{array}$ & $\checkmark$ & $\checkmark$ & $\checkmark$ & $\checkmark$ \\
\hline 8 & $\begin{array}{l}\text { Immediate treatment (within } \\
24 \text { hours after admission) }\end{array}$ & $\checkmark$ & $\checkmark$ & - & - \\
\hline 9 & $\begin{array}{l}\text { Medicines prescribed for the } \\
\text { patient }\end{array}$ & $\checkmark$ & $\checkmark$ & $\checkmark$ & $\checkmark$ \\
\hline 10 & $\begin{array}{l}\text { Date and time of medication } \\
\text { start }\end{array}$ & $\checkmark$ & - & $\checkmark$ & $\checkmark$ \\
\hline 11 & Dosage of drugs & $\checkmark$ & - & - & - \\
\hline 12 & Laboratory tests & $\checkmark$ & $\checkmark$ & $\checkmark$ & $\checkmark$ \\
\hline 13 & $\begin{array}{l}\text { Date and time of laboratory } \\
\text { testing }\end{array}$ & $\checkmark$ & - & - & - \\
\hline 14 & Complications in the hospital & $\checkmark$ & $\checkmark$ & $\checkmark$ & - \\
\hline 15 & $\begin{array}{l}\text { Date of the onset of hospital } \\
\text { complications in the patient }\end{array}$ & $\checkmark$ & - & - & - \\
\hline 16 & $\begin{array}{l}\text { Therapeutic and diagnostic } \\
\text { measures }\end{array}$ & $\checkmark$ & $\checkmark$ & $\checkmark$ & $\checkmark$ \\
\hline 17 & Date and time of action & $\checkmark$ & $\checkmark$ & $\checkmark$ & $\checkmark$ \\
\hline 18 & Release date & $\checkmark$ & $\checkmark$ & $\checkmark$ & - \\
\hline 19 & $\begin{array}{l}\text { Separation of the number of } \\
\text { days admitted to the ICU }\end{array}$ & - & $\checkmark$ & $\checkmark$ & $\checkmark$ \\
\hline 20 & $\begin{array}{l}\text { Medicines given to the patient } \\
\text { during discharge }\end{array}$ & $\checkmark$ & $\checkmark$ & $\checkmark$ & $\checkmark$ \\
\hline 21 & $\begin{array}{l}\text { Advice given to the patient } \\
\text { during discharge }\end{array}$ & $\checkmark$ & - & $\checkmark$ & $\checkmark$ \\
\hline 22 & Clearance destination & $\checkmark$ & $\checkmark$ & - & - \\
\hline 23 & Cause and time of death & $\checkmark$ & $\checkmark$ & $\checkmark$ & $\checkmark$ \\
\hline 24 & $\begin{array}{l}\text { Clinical diagnosis at the time } \\
\text { of discharge (final diagnosis) }\end{array}$ & - & $\checkmark$ & $\checkmark$ & $\checkmark$ \\
\hline 25 & Detection and Action Codes & $\checkmark$ & - & - & $\checkmark$ \\
\hline 26 & Tracking data & - & $\checkmark$ & $\checkmark$ & $\sqrt{ }$ \\
\hline
\end{tabular}

In terms of data analysis, the results showed that data analysis and data distribution were conducted in all three countries. However, in the Iranian registry system, data analysis is limited to the number of patients and their age and sex distribution, and annual reports are presented to provide the number of patients with myocardial infarction, and data analysis is not done in other cases (This is the result of the research findings and as a result of the interview with the specialists of the registration and viewing of their reports). Table 2 compares the analysis of data in selected countries and in Iran.

According to the results, the analysis of the patient's preadmission drugs in Malaysia is done only with aspirin. Analysis of data on the mean time from onset of admission to thrombolysis, diagnostic catheterization, coronary intervention through the skin and coronary bypass in the myocardial infarction registry system in the United States in all cases except thrombolysis and in the registry system in Switzerland only it deals with thrombolysis and coronary intervention through the skin.

In the US-based registry system, analysis of data on drug dosing errors only on GP IIb-IIIa anticoagulants and analysis of prognostic factor data for hospital mortality and death after 30 days only for the risk of death is inside the hospital. In the Swiss registry system, the analysis of data on diagnostic and therapeutic measures is done quickly only for quick medical treatment.

\section{DISCUSSION}

Comparison of data elements in the national registry of myocardial infarction in the countries of the United States, Switzerland, Malaysia and Iran showed that all studied countries have a data dictionary to unify the definitions of data elements. The existence of a data dictionary is important in this regard, which unifies the data-related definitions throughout the country, so that everyone's perception of the data is a single notion. The system of registry in the United States is much more extensive in demographic information than in other countries, and each race is fully introduced. In Malaysia, there are also races in the country, but they have not been addressed in this country in Switzerland, which is why it seems more necessary to have a data element called the race in countries with race diversity.

In the United States, data on the transmission of patients is much more detailed than in other countries, probably due to the wide range of countries in the United States and the number of care facilities in the country, which include the transmission of a patient, his delivery vehicle and the length of the transfer process It has become more important than other countries. The date, time, and dosage of the prescribed prescriptions for the patient are also data elements that have been taken into consideration in the United States more than other countries. One category of data that is unique to the United States than other countries is the category of optional data elements and management data elements that are not available in other countries.

The data element that has been considered in Switzerland more than other countries is the data element of diagnostic measures. Also, one of the unique features of data elements in the Swiss system of registry is the possibility of introducing drugs using a special identification code for each drug, which is not possible in other countries.

The unique feature of data elements in Malaysia is also a data element for tracking patients individually and separately, in other countries this data element is not isolated and tracking patients through interviews with patients to a limited extent. Also, the data elements in the registry systems are comparable with the data elements in the following systems: 
Table 2: Comparison of data analysis in myocardial infarction registry in selected countries.

\begin{tabular}{|c|c|c|c|c|c|}
\hline $\begin{array}{l}\prod_{0}^{0} \\
\sum_{\infty}\end{array}$ & Data Elements & 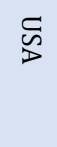 & 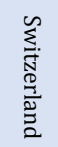 & 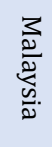 & $\bar{\Xi}$ \\
\hline 1 & Number of patients & $\checkmark$ & $\checkmark$ & $\checkmark$ & $\checkmark$ \\
\hline 2 & Distribution of patient's gender & $\checkmark$ & $\checkmark$ & $\checkmark$ & $\checkmark$ \\
\hline 3 & Distribution of patient's age & $\checkmark$ & $\checkmark$ & $\checkmark$ & $\checkmark$ \\
\hline 4 & $\begin{array}{l}\text { Distribution of patient's race } \\
\text { groups }\end{array}$ & $\checkmark$ & - & $\checkmark$ & - \\
\hline 5 & Insurance status of patients & $\checkmark$ & - & - & - \\
\hline 6 & $\begin{array}{l}\text { The first physician and the first } \\
\text { examining place of the patient }\end{array}$ & $\checkmark$ & - & - & - \\
\hline 7 & Transient status of the patient & $\checkmark$ & $\checkmark$ & - & - \\
\hline 8 & Risk Factors in Patients & $\checkmark$ & $\checkmark$ & $\checkmark$ & - \\
\hline 9 & $\begin{array}{l}\text { Records and history of the } \\
\text { patient }\end{array}$ & $\checkmark$ & - & $\checkmark$ & - \\
\hline 10 & $\begin{array}{l}\text { Drugs used by the patient before } \\
\text { admission }\end{array}$ & $\checkmark$ & - & $\checkmark$ & - \\
\hline 11 & $\begin{array}{l}\text { Mean time to symptoms } \\
\text { beginning before } \\
\text { admission }\end{array}$ & $\checkmark$ & $\checkmark$ & - & - \\
\hline 12 & $\begin{array}{l}\text { Average time from onset of } \\
\text { admission to thrombolysis, } \\
\text { diagnostic catheterization, } \\
\text { coronary intervention through } \\
\text { the skin and coronary artery } \\
\text { bypass }\end{array}$ & $\checkmark$ & $\checkmark$ & - & - \\
\hline 13 & $\begin{array}{l}\text { Signs and symptoms of the } \\
\text { patient during admission }\end{array}$ & $\checkmark$ & - & $\checkmark$ & - \\
\hline 14 & $\begin{array}{l}\text { The time of the patient's } \\
\text { electrocardiogram and its } \\
\text { findings }\end{array}$ & $\checkmark$ & $\checkmark$ & - & - \\
\hline 15 & $\begin{array}{l}\text { Laboratory tests performed for } \\
\text { the patient }\end{array}$ & $\checkmark$ & $\checkmark$ & $\checkmark$ & - \\
\hline 16 & $\begin{array}{l}\text { Number of days of } \\
\text { hospitalization }\end{array}$ & $\checkmark$ & $\checkmark$ & $\checkmark$ & - \\
\hline 17 & Medications given to patients & $\checkmark$ & $\checkmark$ & $\checkmark$ & - \\
\hline 18 & $\begin{array}{l}\text { Medications given in the first } 24 \\
\text { hours after admission }\end{array}$ & $\checkmark$ & $\checkmark$ & - & - \\
\hline 19 & Drug dosing errors & $\checkmark$ & - & - & - \\
\hline 20 & $\begin{array}{l}\text { Diagnostic and therapeutic } \\
\text { measures }\end{array}$ & $\checkmark$ & $\checkmark$ & $\checkmark$ & - \\
\hline 21 & $\begin{array}{l}\text { Diagnostic and therapeutic } \\
\text { measures taken promptly }\end{array}$ & $\checkmark$ & $\checkmark$ & - & - \\
\hline 22 & Clinical Events in the Hospital & $\checkmark$ & $\checkmark$ & - & - \\
\hline 23 & Results of patient treatment & $\checkmark$ & $\checkmark$ & $\checkmark$ & - \\
\hline 24 & $\begin{array}{l}\text { Prognostic factors for hospital } \\
\text { death and death after } 30 \text { days }\end{array}$ & $\checkmark$ & - & $\checkmark$ & - \\
\hline 25 & $\begin{array}{ll}\text { Suggestions during } & \text { the } \\
\text { discharge to the patient } & \\
\end{array}$ & $\checkmark$ & - & - & - \\
\hline 26 & $\begin{array}{l}\text { Medications given to the patient } \\
\text { during discharge }\end{array}$ & $\checkmark$ & $\checkmark$ & - & - \\
\hline 27 & $\begin{array}{l}\text { Center comparison with other } \\
\text { participating centers }\end{array}$ & $\checkmark$ & $\checkmark$ & $\checkmark$ & - \\
\hline 28 & $\begin{array}{l}\text { Center comparison with } \\
\text { national average level }\end{array}$ & $\checkmark$ & $\checkmark$ & $\checkmark$ & - \\
\hline 29 & $\begin{array}{l}\text { Points of compliance with the } \\
\text { clinical guidelines provided to } \\
\text { the centers }\end{array}$ & $\checkmark$ & - & - & - \\
\hline 30 & Patient tracking rates & - & $\checkmark$ & - & - \\
\hline
\end{tabular}

In the global registry of coronary events, the data elements include sixteen categories. From these data, the contra drug indications of the patient are not collected in any of the registry systems examined in this study [16]. Also, in a project called the European Center for Disease Prevention and Control (ECI) project, a compilation of the minimum data set for heart disease in Europe has been addressed. The difference between this research and the present study is that the present study firstly deals only with the comparative study of existing data elements and the identification of the means of differentiation and their sharing in the selected countries, and secondly, only myocardial infarction is specifically considered, but in An audit project, an international project across Europe, has focused on compiling the necessary data elements at the European level for three different categories of cardiovascular disease. In this research, a comparative study between data elements has not been conducted in different countries, and the compilation of data has been carried out according to experts [17]. Keyvanara and his colleagues in 2012 also study the generalities and general structure of the national registry system Myocardial infarction has been addressed in selected countries, in which the study also referred to the need for a national registry of acute coronary syndrome registry in Iran and its structure, but the data elements required for registration have not been mentioned [14]. In a study in India aimed at designing a minimum cardiovascular data set in the country, a comparative study was carried out on this data set in Australia, Canada and the United Kingdom. The main difference between this study and the present study is that in the research Now, only data elements in the cardiovascular disease registry system have been specifically considered, in a research conducted in India, the study and compilation of data elements in all cardiovascular diseases has been addressed [18].

The results of the comparative analysis of the data in the national system for recording myocardial infarction showed that in all three countries, data analysis was systematic, and regular reports from these analyzes were periodically available to authorized users. However, in Iran, which lacks the national registry system, in the registry system of the city of Isfahan, as the pioneering registry system for myocardial infarction, only data is collected and systematic analysis is not carried out on collected data and data analysis On the number of patients, the age distribution and sex distribution of patients (not regular) are limited.

Unique analyzes offered in the United States that do not occur in other countries include:

An analysis of the patient's insurance status, which could be due to the variety of insurance coverage for patients in the United States.

An analysis on the first doctor and the first place of the patient's examination, which can be due to its effect on the outcome of the treatment.

Analysis of drug dosing errors, due to the appropriate feedback to participating centers to prevent possible future errors.

An analysis of the suggestions made during the discharge to the patient, which can be due to the assessment of compliance with the suggestions provided in the clinical guidelines provided to the centers.

The rate of compliance with the clinical guidelines provided to the centers to provide feedback to the Centers of Excellence

An analysis conducted in Switzerland and not carried out in other countries is an analysis of the rate of follow up of patients in each center, which is also likely to be important in terms of feedback to participating centers in the registration.

Data analysis in Malaysia has more order than other countries, and data analysis in this country is done in four distinct parts for 
participating centers, these four sections include patient characteristics, symptoms and cardiac symptoms, Treatment and outcome of the treatment. An analysis conducted in Malaysia and not carried out in other countries includes an analysis of prognostic factors for hospital death and death after 30 days. This analysis is likely to be important due to the relationship between the treatment outcomes and the type of treatment provided to patients.

The results of the study indicate that in all countries the analysis of the number of patients, the gender distribution of patients, the age distribution of patients, the risk factors in patients, the laboratory tests performed for the patient, the number of hospital days, the drugs given to the patient, diagnostic and therapeutic measures taken, results from treatment of patients, comparison of the center with other participating centers and with the national average level. The analysis of these cases in all three countries indicates the importance of analyzing the above.

\section{CONCLUSION}

On the one hand, the lack of a national registry system for myocardial infarction in Iran, on the one hand, has a very high burden on cardiovascular diseases and, in the first place, of coronary artery disease, including myocardial infarction, in terms of pathogenicity and mortality, and the implementation of such a system of records, since this registry system is expected to help improve disease management and prevent its occurrence, it is suggested that the national system for registry of myocardial infarction be established in the country, which in addition to this system of registry $0 n$ the data collection, systematic analysis and reporting of the results will also be addressed by this study, data elements and analyzes of the myocardial infarction registry system in other countries were compared, which could help health care providers in developing standards for collection and analysis in this system. Also, in order to create the same understanding of the data elements among all the participants in this registry system, it is suggested that the data be explained and described in the data dictionary of this registry system.

\section{ACKNOWLEDGEMENTS}

The researchers would like to thank the staff of Cardiology Research Center of Isfahan University of Medical Sciences as well as Health Policy Research Center of Shiraz University of Medical Sciences for their support.

\section{REFERENCES}

1. World Health Organization. Cardiovascular diseases, key facts. [Internet]. 2017 [cited: 2018 Sept 1]. Available from: http://www.who.int/news-room/factsheets/detail/ cardiovascular-diseases-(cvds).

2. Chu C-Y, Lin T-H, Lai W-T. The management and prognostic factors of acute coronary syndrome: Evidence from the Taiwan acute coronary syndrome full spectrum registry. Acta Cardiol Sin. 2017; 33(4): 329-38. PMID: 29033503 DOI: 10.6515/ACS20161205A [PubMed]

3. Smith JN, Negrelli JM, Manek MB, Hawes EM, Viera AJ. Diagnosis and management of acute coronary syndrome: An evidence-based update. J Am Board Fam Med. 2015; 28(2):
283-93.
PMID:
25748771
DOI: 10.3122/jabfm.2015.02.140189 [PubMed]

4. Babalis D. Is quality improvement for treatment of acute coronary syndromes worthwhile? Results from the EQUIPACS trial. [PhD Thesis]. London: National Heart and Lung Institute, Faculty of Medicine, Imperial College London, 2015.

5. Beyranvand MR, Kolahi AA, Ghafelebashi SHR. Characteristics and final diagnosis of patients with primary diagnosis of acute coronary syndrome. Journal of Babol University of Medical Sciences. 2008; 10(3): 76-82.

6. Talaei M, Sarrafzadegan N, Sadeghi M, Oveisgharan S, Marshall T, Thomas GN, Iranipour R. Incidence of cardiovascular diseases in an Iranian population: The Isfahan cohort study. Archives of Iranian Medicine. 2013; 16(3): 138-44. PMID: 23432164 DOI: 013163/AIM.004 [PubMed]

7. Rezaei Hachesu P, Oliyaee A, Safaie N, Ferdousi R. Comparison of coronary artery disease guidelines with extracted knowledge from data mining. J Cardiovasc Thorac Res. 2017; 9(2): 95-101. PMID: 28740629 DOI: 10.15171/jcvtr.2017.16 [PubMed]

8. Bove AA. President's page: Preventing cardiovascular disease is a global effort. J Am Coll Cardiol. 2009; 53(22): 2099-2100.

9. Gliklich RE, Dreyer NA, Leavy MB. Registries for evaluating patient outcomes: A user's guide. $3^{\text {rd }}$ ed. Agency for Healthcare Research and Quality (US); Report No.: 13(14)EHC111: 2014. PMID: 24945055 [PubMed]

10. Pillay M, Noor Hisham A, Zaki Morad MZ, Lim TO, Jamaiyah $\mathrm{H}$, Jaya Purany SP. Patient registries in Malaysia and the role of the clinical research centre of the ministry of health. Med J Malaysia. 2008; 63(Suppl C): 1-4. PMID: 19227669 [PubMed]

11. Ministry of Health Malaysia. About NCVD. [Internet]. 2009 [cited: 2017 Oct 4]. Available from: http:/www.acrm.org.my/ncvd/aboutNCVD.htm.

12. Rezaei Ardani A, Ahmadian L, Kimiyafar K, Rohani F, Ebnehoseini Z. Comparative study of data elements in psychiatric history and assessment forms in selected countries. Journal of Health and Biomedical Informatics. 2016; 3(1): 57-64.

13. Karimi S, Saghaeiannejad Isfahani S, Farzandipour M, Esmaeili Ghayoumabadi M. Comparative study of minimum data sets of health information management of organ transplantation in selected countries and presenting appropriate solution for Iran. Journal of Health Information Management. 2011; 7(Special Issue): 497-505.

14. Keyvanara M, Sadeghi M, Saghaeiannejad Isfahani S, Tadayon H. A comparative review of national registry systems of acute coronary syndrome in selected countries. Journal of Health Information Management. 2012; 9(2): 172179.

15. Jahanbakhsh M. A comparative study for hospital diabetes registry in selected countries and designing a model for Iran [MSc Thesis]. Tehran: Shahid Beheshti university of medical Sciences, School of Allied Medical Sciences, 2005.

16. Center for Outcomes Research. GRACE: Initial forms. [Internet]. 2006 [cited: 2017 Jan 5]. Available from: https://www.outcomesumassmed.org/grace/publicfiles/M ain_GRACE_CRF.pdf

17. Gitt AK, Boyle R, Flynn R, Seabra-Gomes R, Hernandez JM, Indolfi C. Cardiology audit and registration data standards for percutaneous coronary intervention (PCI). A report of the CARDS expert committee on percutaneous coronary 
intervention. [Internet]. 2004 [cited: 2017 Sept 1]. Available from: https://www.escardio.org/static_file/Escardio/EUaffairs/CARDS-dataset-PCI-1104.pdf

18. Bedi, B.S. National efforts for standardization in health informatics. [Internet]. 2008 [cited: 2016 Jan 14]. Available from: http://medinfo.cdac.in/resourses/events/mig-symp08/pdf/presentation/Bedi.pdf. 